\title{
The role of fluid migration and static stress transfer in searching connections between the May 2012 Emilia earthquakes through a fully $3 \mathrm{D}$ finite element modeling
}

\author{
M. Volpe ${ }^{1} \cdot$ A. Piersanti ${ }^{1}$
}

Received: 13 January 2016/Accepted: 2 February 2016/Published online: 18 February 2016

(c) Springer International Publishing Switzerland 2016

\begin{abstract}
On May 20 and 29, 2012, two earthquakes struck the Emilia Romagna region (Northern Italy), with similar mechanisms. The proximity in space and time between the two events required to investigate possible triggering effects in terms of stress transfer or fluid migration. Moreover, the debate concerning fluid extraction-injection activities brought to the appointment of an International Commission (ICHESE), for evaluating relationships between the hydrocarbon exploitation and the seismic activity near the focal zone: the ICHESE conclusive report did not exclude the possibility of a triggering effect associated with explorations, although this appears not supported by robust evidences. On the other hand, there is no agreement between published papers addressing classical triggering mechanisms and in this respect an improved analysis based on 3D numerical modeling is a valuable tool to provide new insights and outcomes. To this aim, we built up a 3D model honoring the complexities of the real Earth, to retrieve the slip patterns on both the rupture planes by implementing finite element computed Green's functions in a linear joint inversion scheme of geodetic data. Then, we inspected possible mechanisms which could have contributed to promote the second event, such as Coulomb stress transfer and natural fluid migration. Our findings suggest that both phenomena are not likely to be responsible for the May 29 earthquake, even if fluid migration was found to have a role in facilitating the
\end{abstract}

M. Volpe

manuela.volpe@ingv.it

A. Piersanti

antonio.piersanti@ingv.it

1 Istituto Nazionale di Geofisica e Vulcanologia, Via di Vigna Murata 605, 00143 Rome, Italy rupture but without reaching hydrofracturing condition. Nevertheless a suprahydrostatic pore pressure is inferred which could have promoted the reactivation of the thrust fault.

Keywords 3D finite element modeling - Source inversion - Earthquake triggering - Stress transfer · Fluid migration - Emilia Romagna 2012 seismic sequence

\section{Introduction}

On May 20 (02:03 UTC) and 29 (07:00 UTC), 2012, two earthquakes of magnitude $\mathrm{M}_{L} 5.9\left(\mathrm{M}_{w} 5.9\right)$ and $5.8\left(\mathrm{M}_{w}\right.$ 5.7) (Scognamiglio et al. 2012), hit Northern Italy, in the Po Plain region (Emilia Romagna), causing important damages to industrial and residential buildings, casualties and the evacuation of several cities. The interested area remains on the central sector of the Northern Apennines outer front and follows the crest of the buried CavoneMirandola anticline. The zone is known to be affected by slow deformation rates due to the northwards motion of the Northern Apennines fold and thrust belt and is characterized by moderate seismicity and medium level of seismic hazard, as classified in the national reference seismic hazard model (MPS Working Group 2004; Meletti et al. 2012). A map of the seismic activity registered in that area during May 2012 is shown in Fig. 1.

The May 20 event was located near the city of Finale Emilia, about $30 \mathrm{~km}$ west of Ferrara. It was preceded by five foreshocks, among which the largest one $\left(\mathrm{M}_{L}=4.1\right)$ occurred two hours before and was the starting point of a long sequence of seismicity. The earthquake focal mechanism indicates reverse faulting, with a $\mathrm{N}-\mathrm{S}$ direction of compression, on a S-dipping $\mathrm{E}-\mathrm{W}$-striking fault segment 
Fig. 1 Map of the seismicity registered in Northern Italy in May 2012

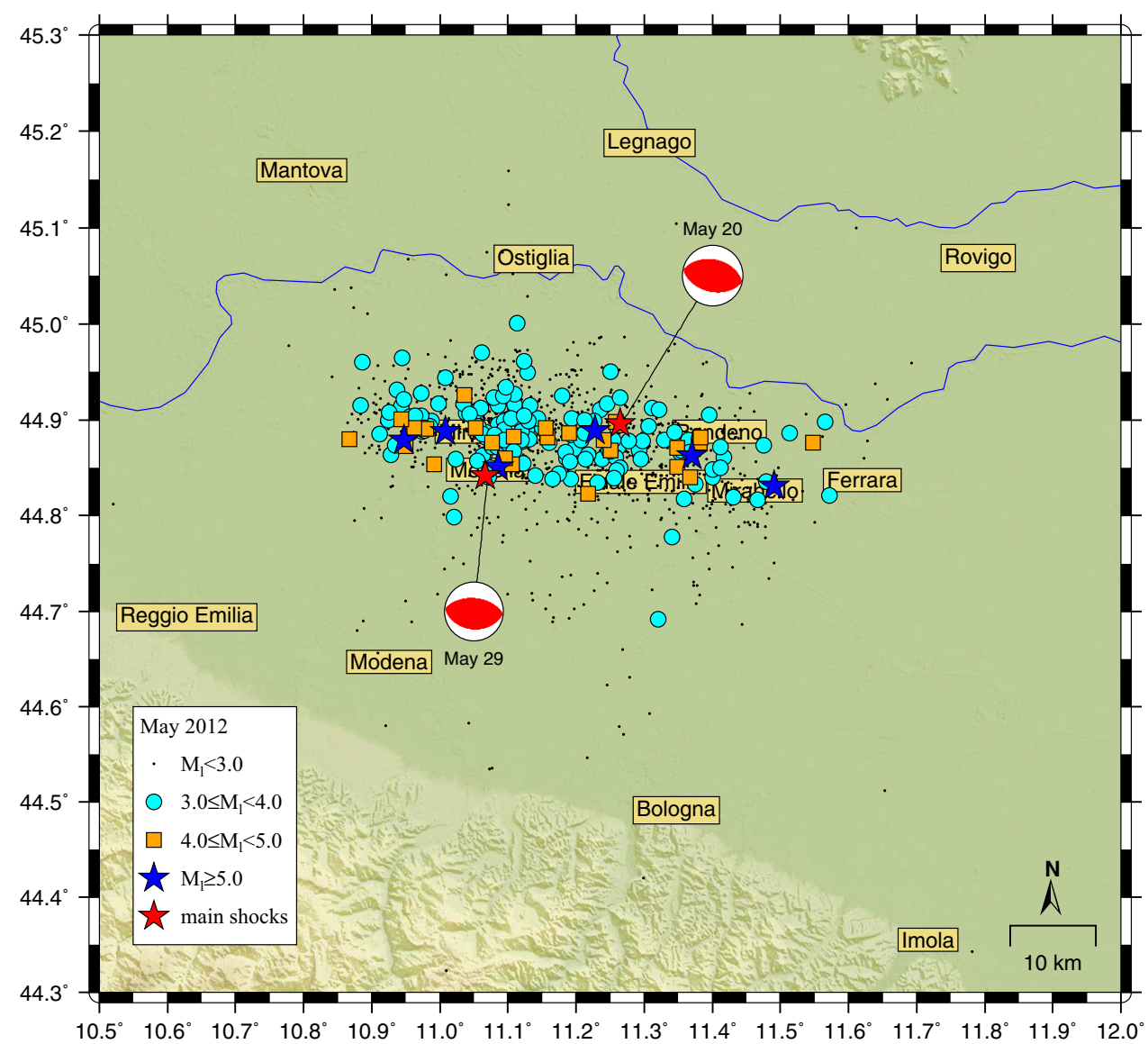

of the inner Ferrara thrust, consistently with the regional tectonic setting (Anzidei et al. 2012).

The May 29 event occurred in the same area, $12 \mathrm{~km} \mathrm{~S}-\mathrm{W}$ of the main shock, in the vicinity of Mirandola. Several authors attributed the rupture either to a distinct adjacent thrust fault segment (i.e. the Mirandola thrust), located to the west, with a similar mechanism (Scognamiglio et al. 2012; Bignami et al. 2012; Govoni et al. 2014) or to a different patch on the same blind low-angle thrust fault (Cesca et al. 2013). Instead, a different interpretation was provided by Tizzani et al. (2013), requiring the activation of three different fault segments and a block roto-translation of the Mirandola anticline.

The occurrence of two events close in space $(\sim 12 \mathrm{~km})$ and time (9 days), showing similarity in magnitude and focal mechanism, raised the need to further understand the connections between the two seismogenic sources as well as to investigate possible triggering effects on fault failure, in terms of tectonic stress transfer or migration of deep fluids. The contribution of hydrocarbon explorations has been largely debated too, so that an international technical-scientific commission was called to evaluate the possible relationships between the increased seismicity and the activities carried out in recent times in the close neighbourhood of the 2012 seismic sequence (ICHESE 2014): special attention was paid to the Cavone oil fields, located within the focal area about $20 \mathrm{~km}$ west of the main shock and close to the second event, in order to asses the role of the fluid extraction-injection activity on the seismic crisis. The Commission ended by considering as highly unlikely that hydrocarbon exploitation have been able to generate induced seismicity, while a triggering effect is not excluded, although not even proved, on the basis of the retrieved "statistical correlations between the increase of seismic activity before the May 202012 event and the increase of production parameters since April/ May 2011. This means that it cannot be ruled out that the combined anthropogenic actions of extraction and injection of fluids in a tectonically active region may have contributed, adding a minute additional load, to the activation of a pre-stressed fault system, already close to the conditions required to produce a significant earthquake" (ICHESE 2014).

Several authors investigated possible connections and triggering effects between the events occurred in the Emilia region on May 2012, but a conclusive outcome has not been achieved yet. Ganas et al. (2012), computing the stress transfer from a coseismic slip distribution model for 
the May 20 rupture, predicted that the May 29 earthquake could have been triggered by slip on the fault caused by the preceding main shock, as its hypocenter is found to lie in the crustal region where static stress was transferred, even if the amount of the loading stress is small. Differently, Convertito et al. (2013), evaluating cumulative changes in the static stress field, reported that static Coulomb stress changes did not significantly contribute to the triggering process, while dynamic triggering, caused by passing seismic waves and enhanced by source directivity, played a primary role in driving the sequence. Cesca et al. (2013), by regional waveform inversion, inferred that the static stress perturbation associated with the May 20 earthquake can not be responsible for the rupture of the Mirandola fault, but it can have sped it up, being the event mature on that fault. Pezzo et al. (2013), by means of geodetic data modeling and stress-transfer analysis, suggested that, although the May 20 event did not produce stress loading at the May 29 hypocenter, a triggering effect could be ascribed to additional stress load redistribution, owing to an aseismic slip occurred on the eastern sector of the Mirandola thrust in the time span between the two shocks.

A stress transfer analysis was also performed by the above mentioned ICHESE (2014) Commission, who calculated the cumulative Coulomb static stress changes on the May 29 failure plane after three events with $\mathrm{M}_{L}>5$ occurred on May 20 (included the main shock): the fault plane of the May 29 rupture is found to be located close to a boundary zone between areas of promoted failure and areas where failure is inhibited. This proximity to the transition zone between $\Delta \mathrm{CFF}>0$ and $\Delta \mathrm{CFF}<0$ provided support to the necessity to consider uncertainties in the stress change analyses, finding a high probability ( $>80 \%)$ of the May 29 rupture to be promoted by the stress change produced by the previous events (ICHESE 2014). It is worth noting that this outcome is basically a statistical estimate and a more robust answer to the problem could be provided by the use of a more realistic and refined numerical model.

Definitely, the issue concerning the triggering between the main events of the May 2012 Emilia sequence remains still unsolved. In fact, previous analyses based on okadastyle modeling of fault interactions (Ganas et al. 2012; Pezzo et al. 2013) have not reached conclusive evidence on the effect of static stress transfer, while dynamic triggering as suggested by Convertito et al. (2013) could be not a robust explanation for two failures separated by a time window of 9 days, since the dynamic effect is likely to vanish few hours after the rupture.

On the other hand, as for other seismic sequence in the Apennines, fluids hosted in the folded sedimentary successions could have been involved in modulating the seismicity during the 2012 Emilia sequence (Calderoni et al. 2009; Govoni et al. 2014). Overpressure-induced effects have been inferred for the Umbria-Marche 1997 seismic sequence in northern Apennines (Miller et al. 2004): the structural and seismic response of this sequence supported a scenario where the coseismic release and propagation of high pressure fluids triggered aftershocks by significantly reducing the effective normal stress. An increment of pore fluid pressure was also found for the April 2009 L'Aquila seismic activity by Di Luccio et al. (2010), who accounted the pore pressure diffusion as the main mechanism controlling the space-time distribution of aftershocks. Malagnini et al. (2012) showed that a secondary structure north of L'Aquila was activated after the April 6, 2009 main shock, due to the effects of the migrating pore fluid pressure field, which dominated the strength of the structure for at least six days and led it to multiple failures. Ventura and Di Giovambattista (2012), analyzing the spatial and temporal evolution of the MayJune 2012 Emilia seismic sequence, concluded that the earthquakes interested two buried coalescing thrusts of Northern Apennines which were activated by the presence of compressive regime and suprahydrostatic pore pressure.

In the present work we use a fully 3D finite element (FE) modeling to perform a source inversion analysis for the May 20 and 29 earthquakes and investigate static stress triggering effects between the two earthquakes. We also inspect the possible role of deep fluid flow in promoting the second event. The paper is organized as follows: "The FE model" describes the 3D FE model for the study area; "Geodetic data" resumes the geodetic datasets used in the present work; results of the inversions performed to retrieve the source models are discussed in "Source inversions"; in the next sections the "Stress transfer analysis" and the "Fluid pressure estimate" were discussed; conclusive remarks are summarized in "Conclusions".

\section{The FE model}

Our modeling is based on a 3D FE approach which allows us to perform inverse analysis of the static deformation field from computed Green's functions. The FE model is built up by Cubit (Casarotti et al. 2008), a powerful mesher tool suite from Sandia National Laboratories (http://cubit. sandia.org), while FE simulations are carried out through the numerical simulation tool FEMSA, which is an acronym for "Finite Element Modeling for Seismic Applications" (Volpe et al. 2007, 2011) and takes advantage of the free solver CalculiX (http://www.calculix.de) (Dhondt 2004).

For the present study, we built up a 3D simulation domain $\sim 80 \mathrm{~km}$ thick, spanning a surface of about 30, 000 $\mathrm{km}^{2}$ in Northern Italy. Real surface topography with $500 \mathrm{~m}$ 
spatial resolution, obtained from the Shuttle Radar Topography Mission (SRTM) $90 \mathrm{~m}$ digital elevation data (http://www2.jpl.nasa.gov/srtm/), has been incorporated within the model.

The volume was discretized using 20-nodes brick elements: due to the large extent of the simulation domain, a trade-off between a good mesh resolution and a sustainable computational cost was mandatory. To this aim, the whole volume was split into sub-volumes which have been separately meshed and then glued through equations based on the shape functions of the element type.

The top surface, considering the absence of topographical reliefs in the investigated area, was meshed with a structured mesh imposing an element size of about $1 \mathrm{~km}$. Under the surface, within the first $40 \mathrm{~km}$, the horizontal element size was biased from $\sim 500 \mathrm{~m}$ in the fault zone to $\sim 5 \mathrm{~km}$ at the edges, using the paving meshing algorithm, which allows for easy transitions between dissimilar sizes of elements and element size variations based on sizing functions (White and Kinney 1997). The vertical size was fixed at $1600 \mathrm{~m}$. For the bottom slice, at depths greater than $40 \mathrm{~km}$, a structured coarser mesh was generated using the submap scheme and setting the element size to $5 \mathrm{~km}$. The whole mesh contains 2,321,945 elements and 9,489,253 nodes.

The model is governed by elastic behaviour. We considered a 3D tomographic model for the Italian peninsula derived by the inversion of $\mathrm{P}$-wave travel time measurements (Di Stefano et al. 2011). The $\mathrm{v}_{p}$ velocity model is scaled into $\mathrm{v}_{s}$ and density using a scaling relationship (Magnoni et al. 2014). Local features like sedimentary basins are defined by superimposing the $\mathrm{v}_{s} 30$ layer, i.e. the shear-wave velocities over the uppermost 30 $\mathrm{m}$ (Michelini et al. 2008). An image of the meshed model is shown in Fig. 2.

To implement the seismic sources for the 2012 Emilia earthquakes, we adopted the geometries proposed by Pezzo et al. (2013), who retrieved the fault planes for the May 20 and 29 events by means of the inversion of InSAR and GPS data, using the analytical solutions for dislocations in an elastic half-space (Okada 1985). Due to the quite good geodetic coverage for these events (Serpelloni et al. 2012), the obtained source models turn out to be relatively detailed. The May 20 source model consists in a variable dip structure, corresponding to the middle Ferrara thrust, with a shallower segment, $34 \times 11 \mathrm{~km}$ wide, dipping at $40^{\circ} \mathrm{SSW}$, followed at depth by a $20^{\circ} \mathrm{SSW}$ dipping segment, $34 \times 12 \mathrm{~km}$ wide. The two sub-planes are subdivided into 184 rectangular patches each and the strike and rake angles are fixed at $114^{\circ}$ and $90^{\circ}$, respectively. Similarly, the May 29 source model, approximating the shape of the frontal Mirandola thrust and striking at $95^{\circ}$, is made up by an upper segment $(32 \times 7.5 \mathrm{~km})$ dipping at $45^{\circ} \mathrm{S}$ and a lower segment $(32 \times 10 \mathrm{~km})$ with $\operatorname{dip}=30^{\circ}$. The two subplanes are subdivided into 126 and 147 patches, respectively, and the rake angle is $85^{\circ}$.
Fig. 2 Image of the 3D simulation volume, viewed from $\mathrm{SW}$. The compressional wave velocity from the adopted tomographic model (see text) and the FE mesh are shown. Topographic reliefs have been enhanced for a better visualization

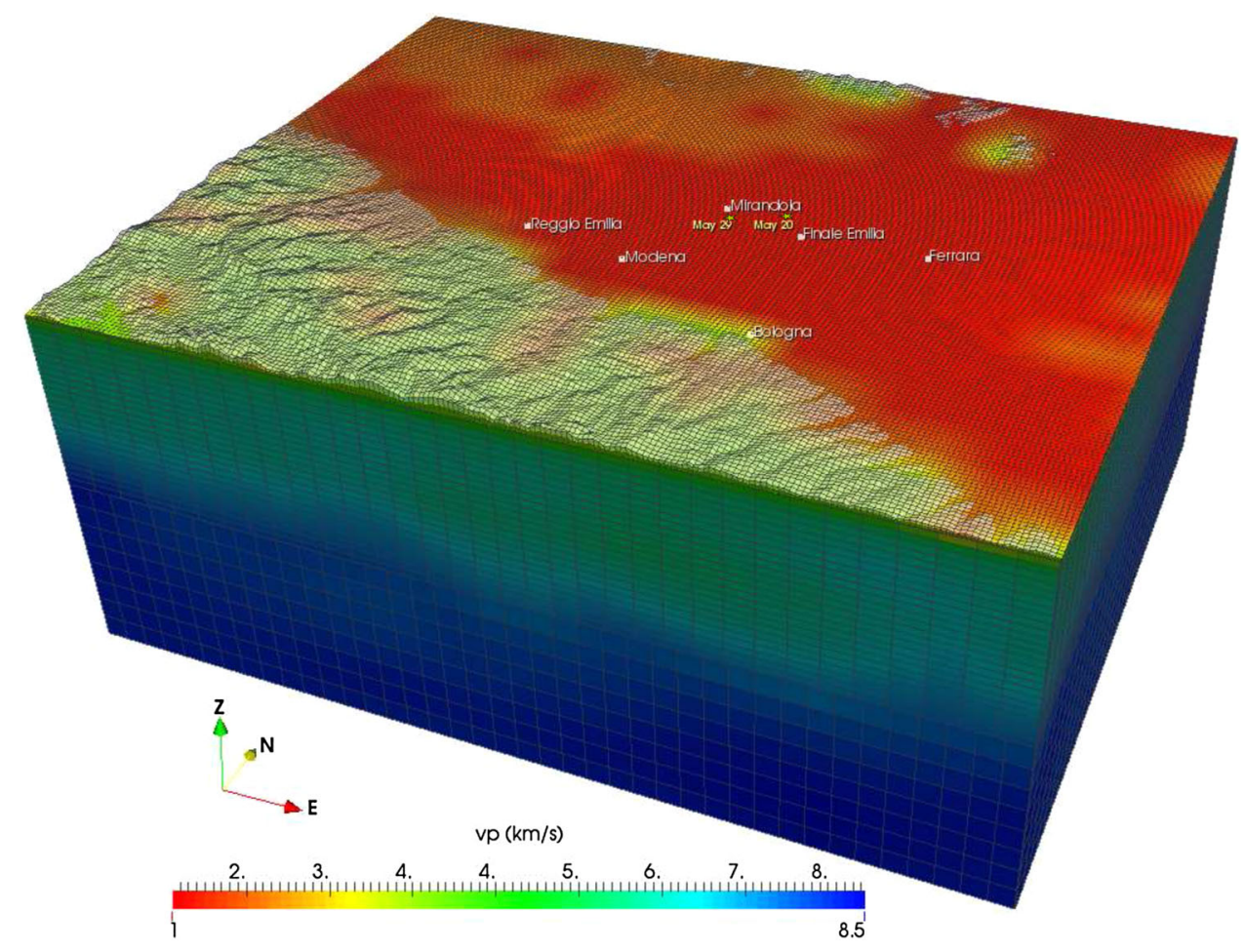




\section{Geodetic data}

We used coseismic deformation data derived from GPS measurements (Serpelloni et al. 2012) and InSAR deformation maps acquired from COSMO-SkyMed (CSK) and Radarsat-1 (RSAT) satellites (Pezzo et al. 2013).

Serpelloni et al. (2012) provided the coseismic offsets retrieved from continuous GPS stations operating in and around the epicentral area. From the complete available datasets, we extracted two subsets of 41 and 43 measurements related to the May 20 and 29 events respectively, since the remaining stations are outside our simulation domain. The resulting datasets are referred to as GPS_20 and GPS_29.

Two CSK interferograms were generated by Pezzo et al. (2013), one capturing the easternmost part of the ground displacements of the first earthquake (hereinafter CSK1) and the other yielding a well-centered picture for the second shock (hereinafter CSK2). A third interferogram was calculated from a RSAT pair spanning the seismic activity from May 12th to June 5th and showing a cumulating displacement field: to obtain a full displacement field for the May 20 event, a differential map was generated by subtracting the CSK2 deformation map from the RSAT one (hereinafter RSAT-CSK2) (Pezzo et al. 2013). The InSAR datasets were sampled at the meshed domain surface, resulting in 2, 870 punctual displacements related to the main shock (364 from CSK1 and 2506 from RSAT-CSK2) and 1695 data from CSK2 for the second shock.

\section{Source inversions}

The coseismic deformation data were inverted in order to retrieve the slip distributions on the rupture planes for both the Emilia 2012 main events. Therefore, we composed the Green's function matrix by imposing a unitary slip on each patch and carrying out direct FE simulations to compute static displacements. Then, we performed a series of linear inversions of the geodetic data and solved the system $\underline{u}_{o b s}=\mathcal{G} \cdot \underline{d}$, where $\underline{u}_{o b s}$ is the vector of the observed displacements, $\mathcal{G}$ is the Green's function matrix and $\underline{d}$ is the slip vector. To this aim we used the damped least squares (DLS) analytical method according to the equation (Volpe et al. 2012, 2015):

$$
\begin{aligned}
\underline{d}_{e s t}= & \underline{d}_{0}+\left(\mathcal{G}^{T} \cdot \mathcal{W} \cdot \mathcal{G}+k^{2} \cdot \mathcal{D}^{T} \cdot \mathcal{D}\right)^{-1} \\
& \cdot \mathcal{G}^{T} \cdot \mathcal{W} \cdot\left(\underline{u}_{o b s}-\mathcal{G} \cdot \underline{d}_{0}\right),
\end{aligned}
$$

where $\underline{d}_{e s t}$ is the estimated slip vector, $\underline{d}_{0}$ is an arbitrary slip vector acting as initial condition (set as null slip condition), $\mathcal{W}$ is the data weight matrix, $k$ is an empirical coefficient (Menke 1989) and $\mathcal{D}$ the discrete approximation of the
Table 1 RMS of residuals (in units of $\mathrm{cm}$ ) between observed and modeled coseismic displacements obtained from the joint inversion of GPS and InSAR data for the 2012 May 20 and 29 events

\begin{tabular}{llll}
\hline May 20 & \multicolumn{3}{c}{ May 29 } \\
\hline GPS_20 & 0.66 & GPS_29 & 0.65 \\
CSK1 & 1.1 & CSK2 & 4.3 \\
RSAT-CSK2 & 2.8 & & \\
\hline
\end{tabular}

Laplacian operator. The term $k^{2} \cdot \mathcal{D}^{T} \cdot \mathcal{D}$ is used to damp the singularity of the $\mathcal{G}$ matrix and regularize the inversion (Boschi 2006). The model misfit with respect to the observed data was evaluated in terms of root mean squares (RMS) of residuals computed for the 3D displacement field (Table 1).

The inferred source models are shown in Fig. 3 and are consistent with results from Pezzo et al. (2013).

The May 20 rupture pattern (Fig. 3a) evidences a large high slip area mostly localized in the upper zone of the fault plane, starting at about $3 \mathrm{~km}$ (along-dip) from the top, very close to the hypocenter, and extending in the east direction and down-dip. This distribution corresponds to a released seismic moment $\mathrm{M}_{0}=2.08 \times 10^{18} \mathrm{~N}$ m and reaches the maximum slip value of about $70 \mathrm{~cm}$ at a depth of about $5 \mathrm{~km}$.

On the contrary, for the May 29 event, a more heterogeneous slip pattern is obtained (Fig. 3b), having two principal slip patches, one located in the central part of the rupture plane, in correspondence of the hypocenter, and one in the south-western corner. This patch features the peak value of the distribution, which is about $56 \mathrm{~cm}$ and is reached at about $9 \mathrm{~km}$ depth. A secondary maximum (45 $\mathrm{cm}$ ) occurs on the first patch at a depth of about $6 \mathrm{~km}$, just above the hypocenter. The slip release appears more spread with respect to the previous pattern, but produces roughly the same seismic moment $\left(\mathrm{M}_{0}=2.09 \times 10^{18} \mathrm{~N} \mathrm{~m}\right)$.

Despite the overall agreement with respect to the source models obtained by Pezzo et al. (2013), we note some differences between the inverted patterns, likely due to the impact of 3D complexities. Namely, for the May 20 earthquake our slip distribution is slightly more spread in the western and deeper part of the fault plane, while for the second event the western patch is located deeper on the fault and appears more evident with respect to the uniform model.

\section{Stress transfer analysis}

Fault interaction occurs when a seismic event perturbs the stress state at distance from the hypocenter and the probability of a subsequent earthquake may be affected by this 


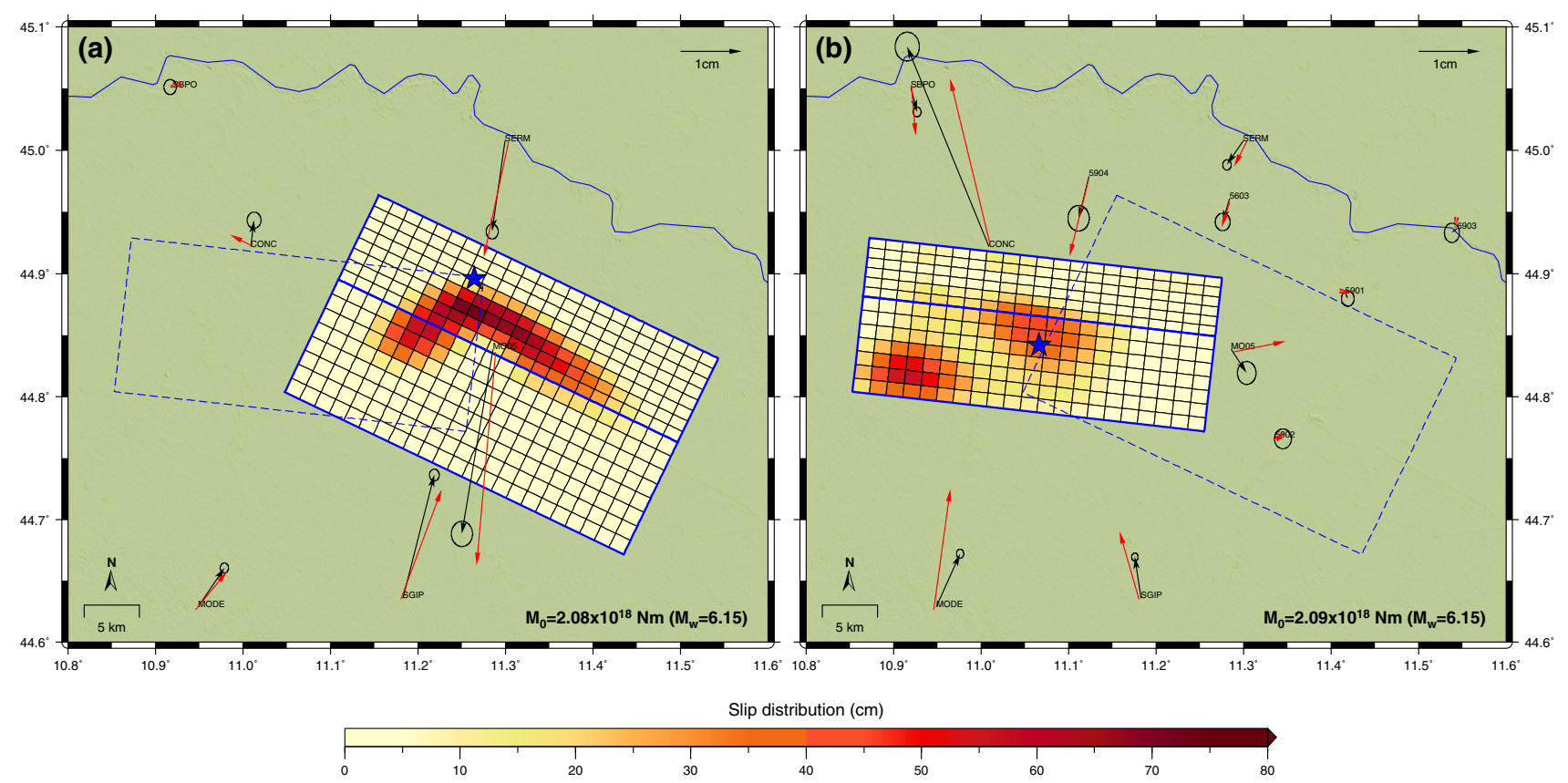

Fig. 3 Source models retrieved from the joint inversions of GPS and DInSAR data for the May 20 (a) and 29 (b) events. The dotted rectangles represents the contours of the May 29 (a) and 20

stress changes (Stein 1999). In such a case, purely seismotectonic stress transfer is involved and the second event can be triggered or hastened, if fault conditions are close to failure.

Static and quasi-static stress changes can be quantitatively described by the Coulomb failure function (CFF), which can be employed to investigate the probability of successive earthquakes occurring around a source fault. The variation of CFF on a receiver fault caused by slip on a source fault is defined as

$\Delta \mathrm{CFF}=\Delta \tau+\mu\left(\Delta \sigma_{n}+\Delta P\right)$

where $\Delta \tau$ is the shear stress change (positive in the fault slip direction), $\Delta \sigma_{n}$ is the normal stress change (positive for extension), $\mu$ is the friction coefficient and $\Delta \mathrm{P}$ indicates the pore pressure changes, representing the undrained response of the medium on a sufficiently short timescale so that fluid flow cannot occur; at longer timescales the drained response of the medium will modify the pore pressure evolution promoting fluid flow (Steacy et al. 2005). A possible undrained pore pressure model is the constant apparent friction model, in which pore pressure is proportional to normal stress changes and Eq. 2 becomes

$\Delta \mathrm{CFF} \simeq \Delta \tau+\mu^{\prime} \Delta \sigma_{n}$

where the apparent friction coefficient $\mu^{\prime}$ is intended to include the effects of pore fluids as well as the material properties of the fault zone (Harris 1998; Cocco and Rice 2002; Steacy et al. 2005). Positive or negative variations of (b) faulting sources, respectively. GPS modeled (red) and observed (black) displacements are also shown

the CFF indicate that the stress field is acting to promote or oppose the rupture, respectively. In the literature, a CFF increase of the order of 0.1 bar $(0.01 \mathrm{MPa})$ is commonly considered a threshold for effective triggering of seismic events, though there are no conclusive evidences for this (Harris 1998).

We investigated the role of the main shock on promoting the second rupture 9 days later by means of a stress transfer analysis based on the CFF evaluation. To this aim, we firstly computed the stress tensor corresponding to the elastic dislocation induced by the May 20 earthquake (i.e. the source fault), through direct FE simulation, using the source model retrieved from the linear inversion (Fig. 3a). We then projected it onto the fault plane of the May 29 earthquake (i.e. the receiver fault) and assessed the effect on the rupture mechanism by calculating the CFF variations, according to Eq. 3, in order to evaluate whether the main shock contributed to bring the fault of the May 29 event closer to failure. We fixed $\mu^{\prime}=0.4$ (Cocco and Rice 2002; Ganas et al. 2012; Pezzo et al. 2013).

The CFF analysis is plotted in Fig. 4 and gives rise to two comments. Firstly, a positive Coulomb stress change is observed at the eastern edge of the May 29 fault and, secondly, the CFF variation anywhere near the hypocenter is definitely negative. These outcomes suggest that the May 29 earthquake neither was directly triggered by the main shock through static Coulomb stress redistribution, as otherwise $\triangle \mathrm{CFF}$ should have been positive at the hypocenter, nor can be connected to the positive stress 
Fig. 4 Result of the CFF analysis performed using the May 20 source model (dotted rectangle) inferred from the joint inversion to calculate the Coulomb stress changes on the May 29 plane

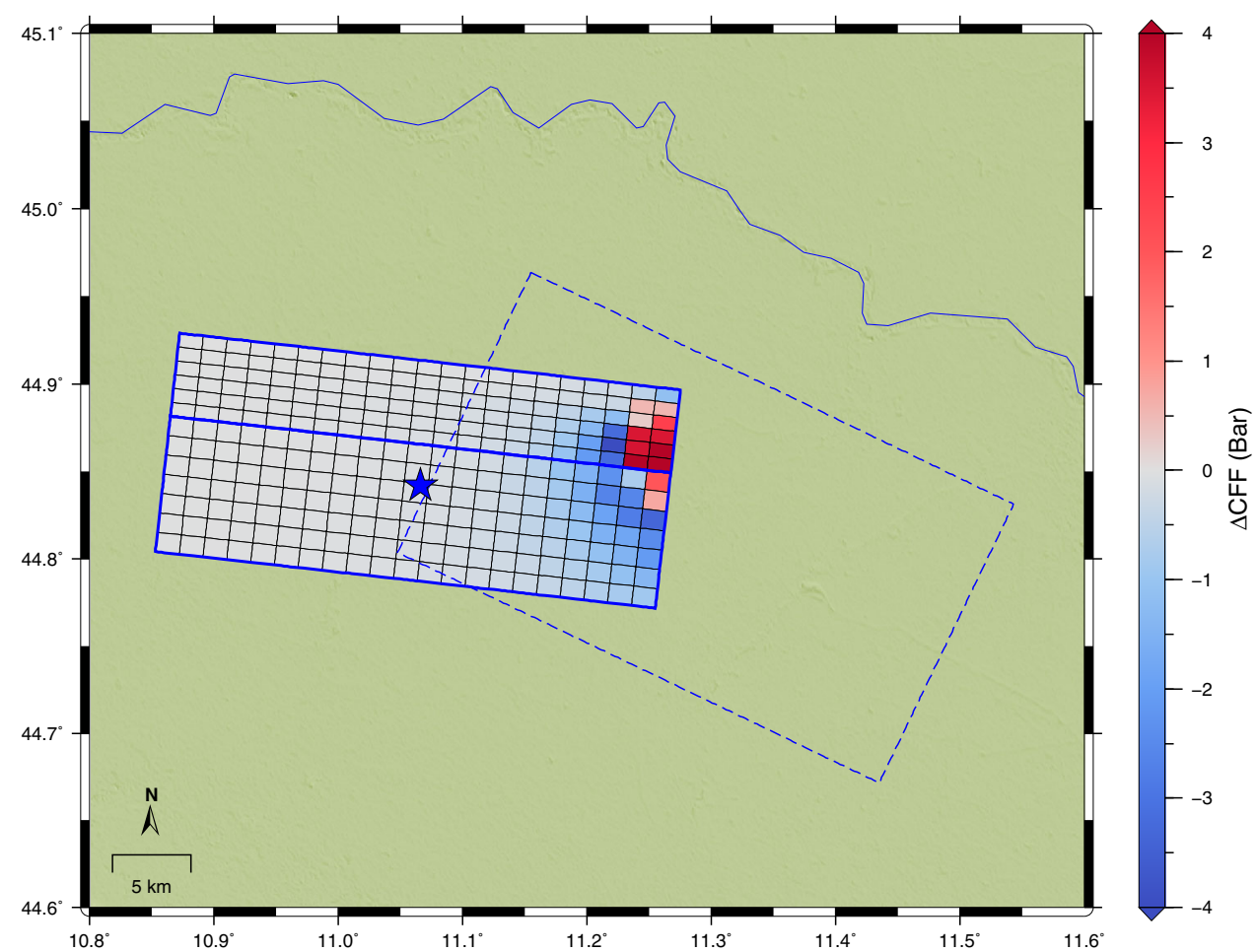

changes observed at the eastern edge, as in such a case the rupture would be initiated in that sector of the fault plane.

A similar pattern of $\triangle \mathrm{CFF}$ is obtained by Pezzo et al. (2013), who associated the eastern positive patch to an aseismic slip subsequent to the May 20 event, accounted as responsible for a whisker-shaped deformation pattern visible in the RSAT-CSK2 interferogram. In the author's opinion, the aseismic afterslip could have played an important role in triggering the May 29 rupture due to stress redistribution (Pezzo et al. 2013). In other words, after the main shock, the seismo-tectonic stress transfer would have induced an aseismic slip at the eastern edge of the second shock fault plane. This aseismic slip in turn could have triggered the May 29 rupture.

We inspected such a possible mechanism by inverting the whisker-shaped deformation pattern on the May 29 rupture plane and then computing the $\mathrm{CFF}$ variations due to the retrieved slip distribution. Figure 5 provides the result of the inversion: a clear slip patch can be observed at the eastern edge of the plane, exactly where the CFF analysis predicted. As this slip release can not be associated with any significant earthquake, it may represent the aseismic slip guessed by Pezzo et al. (2013), occurred in a time span between the two main events and responsible for the whisker-shaped deformation observed in the interferogram. If this slip release would have triggered the May 29 rupture through static stress transfer, the CFF variations associated with this distribution would be expected to be positive near the hypocenter. Instead, as shown in Fig. $6, \Delta$ CFF turns out to be still negative everywhere on the fault plane.

Our findings suggest that a mechanism based on static Coulomb stress transfer is not involved in triggering the May 29 event, as the stress perturbation due to the May 20 main shock does not appear to be responsible for the second rupture. Even the hypothesis of an indirect effect mediated by an aseismic slip, as suggested by Pezzo et al. (2013), is ruled out by our analysis.

To try and discover the actual link between the two earthquakes, in the next section we will address the possible role of fluid in promoting the failure.

\section{Fluid pressure estimate}

Fluids can play an important role in seismogenic processes, as pore pressure increases tend to reduce the strength of the fault and can trigger earthquake activity (Di Luccio et al. 2010; Malagnini et al. 2012). Geological data for the study area reveal the presence of gas and brines hosted in Cretaceous and Miocene terrains as well as evaporites of the Mesozoic-Triassic sequence which may maintain high fluid pressure at depth due to their low permeability (Ventura and Di Giovambattista 2012). Evidence of deep fluids playing a role in the seismic release was also highlighted by Calderoni et al. (2009) in Northern Apennines, while Govoni et al. (2014), performing a complete analysis 
Fig. 5 Slip pattern obtained from the inversion of the RSAT-CSK2 dataset on the rupture plane of the May 29 event. The inferred slip patch located at the eastern edge is associated to the whiskershaped deformation observed in the interferogram by Pezzo et al. (2013) and is supposed to be an aseismic slip occurred in a time span between the two shocks

Fig. 6 Result of the CFF analysis performed using the aseismic slip inferred from the inversion of the RSAT-CSK2 dataset (Fig. 5) to calculate the Coulomb stress changes on the May 29 plane
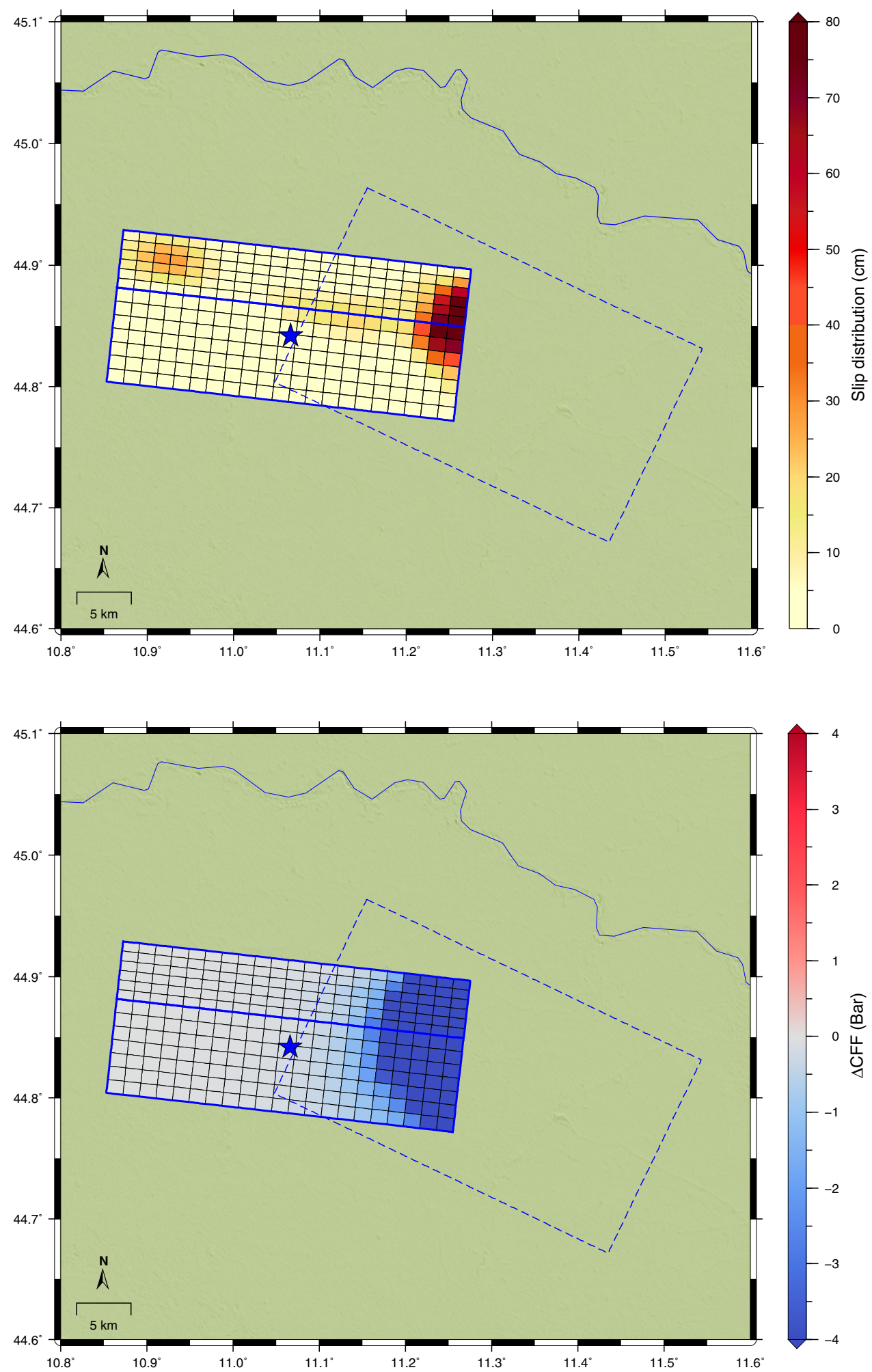

of the 2012 Emilia seismic sequence by accurate aftershock location, related the retrieved high $\mathrm{Vp} / \mathrm{Vs}$ values to fractured and fluid saturated Mesozoic carbonates.

As reported in the Introduction, for the May 29 event a possible induction by anthropogenic activity connected to fluid injection and extraction has been suggested and widely debated and the International Commission on Hydrocarbon Exploration and Seismicity in the Emilia Region was appointed to answer the question if it is "possible that the Emilia seismic crisis has been triggered 
by activities for the exploitation and utilization of reservoirs carried out in recent times in the close neighbourhood of the seismic sequence of 2012" (ICHESE 2014). The attention was particularly focused on the Cavone reservoir but, from the pressure recordings, water injection is found to entail a pressure perturbation acting only locally around the well, since a rapid dissipation of pore pressure is observed during no flow period (ICHESE 2014). A similar conclusion is achieved by the Cavone Monitoring Laboratory, indicating that the average fluid pressure decreases in the vicinity of the field, while pressure increases occur just near the injection wells and are highly localized to distances within 1-2 km (Astiz et al. 2014). Nevertheless, owing also to the lack of evidences for a clear non-anthropogenic triggering mechanism, as shown in the previous section, the ICHESE (2014) Commission did not completely ruled out the possibility of a triggering effect associated with hydrocarbon exploration activities.

In order to inspect the contribution of natural deep fluid dynamics to the seismic release, we estimated the fluid pressure acting on the May 29 rupture plane, following the method developed by Fournier (1996) and applied by Calderoni et al. (2009) and Ventura and Di Giovambattista (2012) to Northern Apennines. According to such a method, the Coulomb failure criterion is given by the following analytical expression:

$$
\left(\sigma_{1}-\sigma_{3}\right)=\left[2 \mu\left(\sigma_{3}-\lambda \sigma_{v}\right)+2 C\right] /[(1-\mu \tan \theta) \sin 2 \theta]
$$

where $\sigma_{1}$ and $\sigma_{3}$ are the maximum and minimum principal stresses, $\mu$ is the coefficient of internal friction, $C$ is the cohesion, $\theta$ is the angle between $\sigma_{1}$ and the fault plane and $\lambda$ is the pore fluid factor defined as the ratio between the fluid pressure $P_{f}$ and the vertical (lithostatic) load $\sigma_{v}$. We set $C=0$, assuming that the rupture occurred on a preexisting thrust (for the intact rock, $C=10 \mathrm{MPa}$ ), and $\mu=$ 0.6 (Calderoni et al. 2009; Di Luccio et al. 2010; Ventura and Di Giovambattista 2012).

We adopted the tectonic thrust faulting stress regime defined as $\sigma_{3}^{t}=\sigma_{v}$ and $\sigma_{1}^{t}=\sigma_{H}$, being $\sigma_{H}$ the regional maximum horizontal stress (Anderson 1951). Considered that $\sigma_{v}=\rho g h$, where $\rho$ is the rock density ( $\rho=2650 \mathrm{~kg}$ $\left.\mathrm{m}^{-3}\right), g$ is the gravity and $h$ is the thickness of overburden, and that $\sigma_{H}$ was found to increase with depth at $50 \mathrm{MPa}$ $\mathrm{km}^{-1}$ (Ventura and Di Giovambattista 2012; Mariucci and Müller 2003), we computed the absolute values of the fluid pressure $P_{f}^{t}$ on the May 29 fault plane due to the tectonic stress, which is shown in Fig. 7a, while in Fig. 7b the ratio between $P_{f}^{t}$ and the minimum principal stress $\sigma_{3}^{t}$ is provided. These plots reveal a suprahydrostatic pore pressure within the hypocentral area with $P_{f}^{t}<\sigma_{3}^{t}$, meaning that the $P_{f}^{t}$ values are not sufficient to induce hydrofracturing, which requires $P_{f}^{t}>\sigma_{3}^{t}$. The suprahydrostatic regime is known to reduce the stresses required for brittle failure (Streit and Cox 2001) and can be supposed to have played a significant role in reactivating the fault, as already found for other thrust systems as well as in the Emilia Romagna

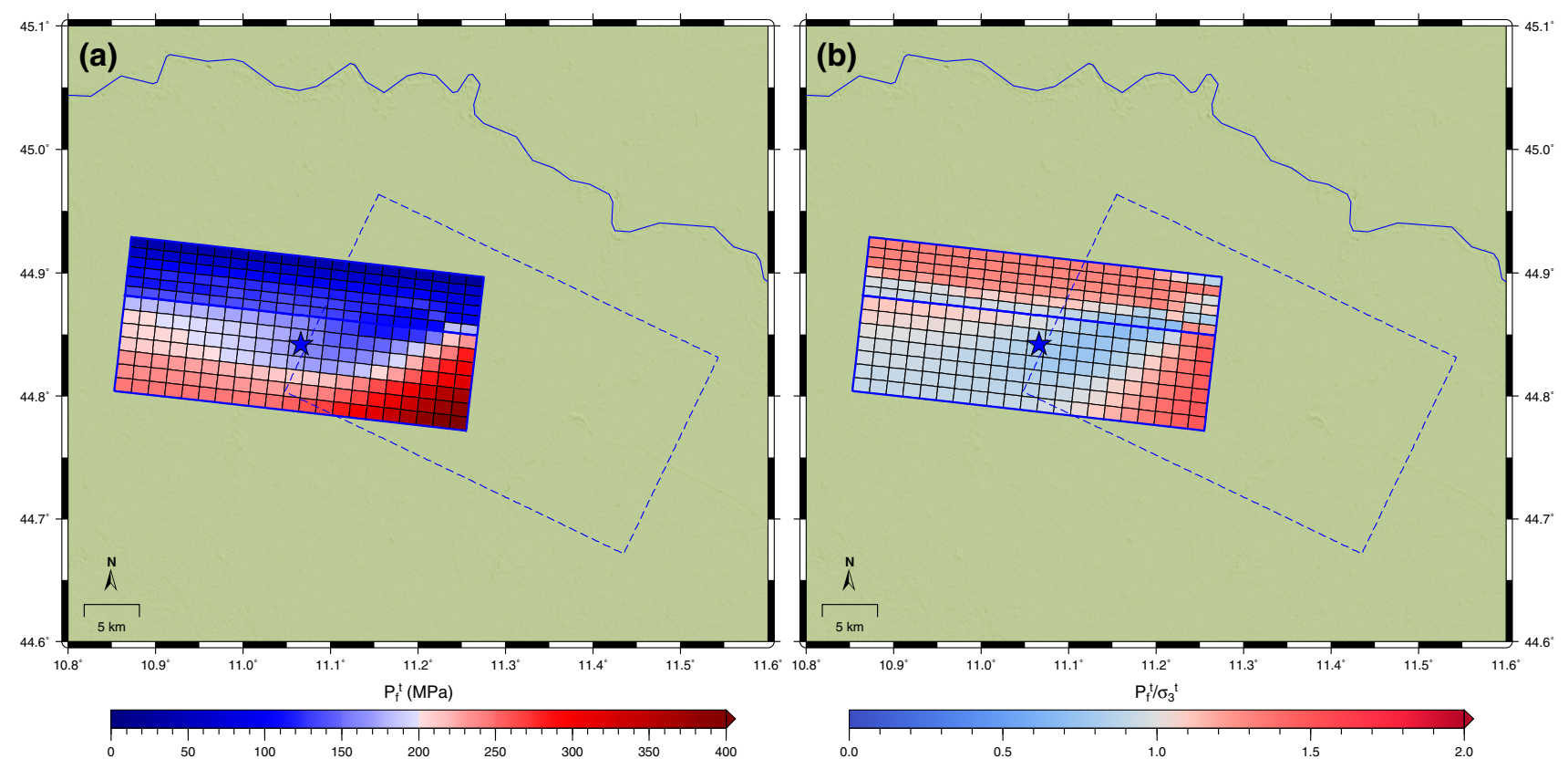

Fig. 7 a Fluid pressure $\left(P_{f}^{t}\right)$ absolute values due to the tectonic stress computed on the May 29 fault plane; $\mathbf{b}$ ratio between $P_{f}^{t}$ and the minimum principal stress $\sigma_{3}^{t}$ 


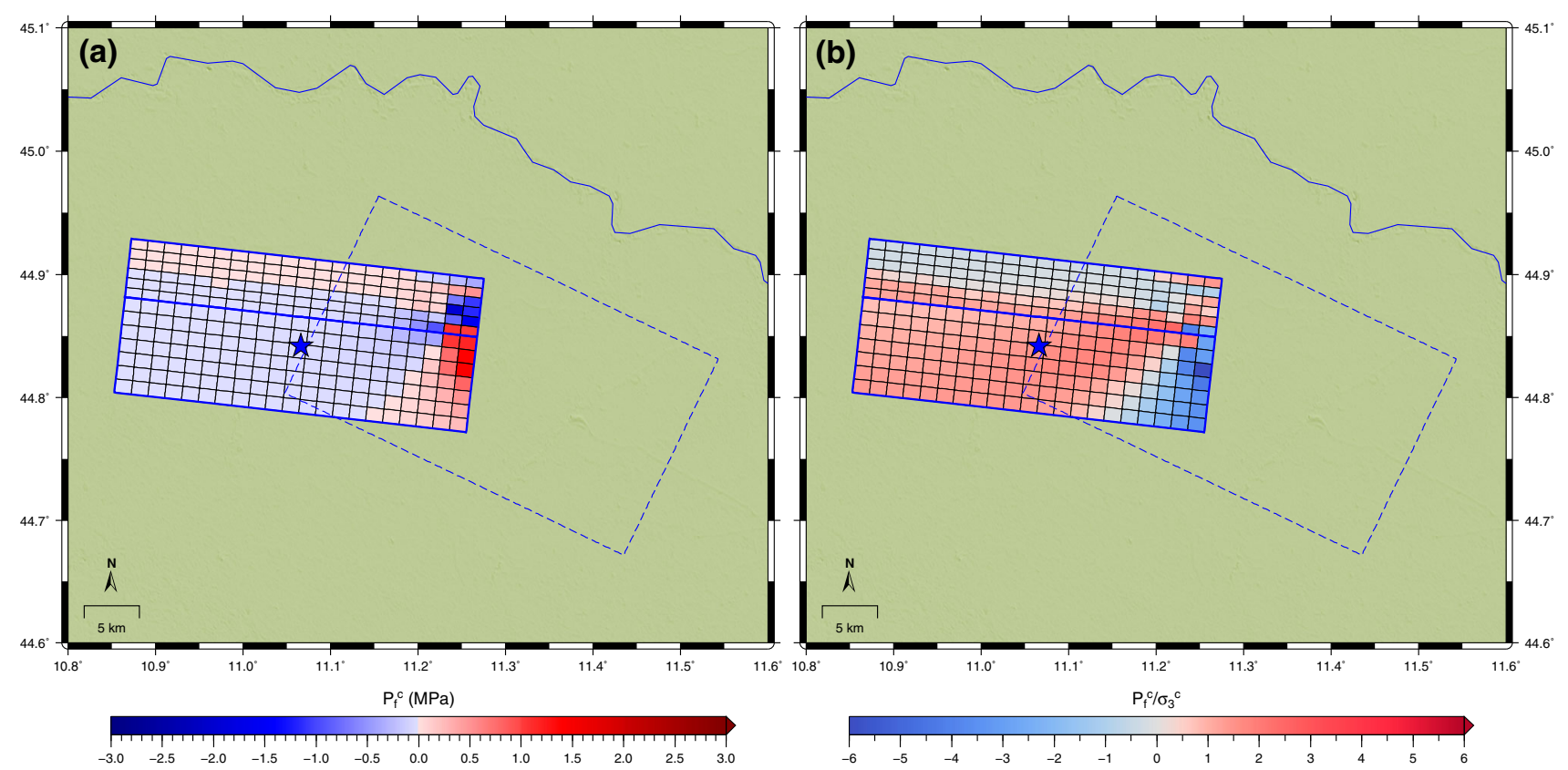

Fig. 8 a Fluid pressure $\left(P_{f}^{c}\right)$ values computed on the May 29 fault plane due to the May 20 coseismic stress field; b ratio between $P_{f}^{c}$ and the minimum principal stress $\sigma_{3}^{c}$

Apennines (Ventura and Di Giovambattista 2012). The involved fluids could be gas and brines hosted in the stratigraphic folds.

We then computed the variation of the pore pressure due to the stress field generated by the main shock, using the Eq. 4, where the principal stresses are now calculated as the eigenvalues of the stress tensor obtained from the direct simulation of the May 20 event. The result is shown in Fig. 8: the main shock impresses a compressive (coseismic) pressure on the May 29 fault plane, being the associated $P_{f}^{c}<0$ within the hypocentral area as well as in all the south-western portion of the plane (Fig. 8a). Moreover, in Fig. $8 \mathrm{~b}$ we observe that in almost the same zone, which is basically the region where slip release is observed in the inverted model (Fig. 3b), this pressure overcomes the values of the minimum principal stress $\sigma_{3}^{c}$ produced by the main shock, which can be interpreted as a contribution promoting the hydraulic failure, although the condition for hydrofracturing remains unsatisfied by the total fluid pressure, i.e. the combined tectonic and the coseismic pressures.

\section{Conclusions}

We investigated the possible connections between the main events of the 2012 Emilia seismic sequence occurred on May 20 and 29, in order to clarify the role played by static stress transfer and deep fluid migration on the occurrence of the May 29 earthquake after the first shock. For this purpose, we adopted a 3D FE model incorporating surface topography and complex rheological heterogeneities, deduced from seismic tomography. We used the source models proposed by Pezzo et al. (2013).

We firstly retrieved the slip distributions on the rupture planes through linear joint inversion of geodetic deformation data (GPS and InSAR), upon computation of the Green's function matrix by means of 3D FE simulations. The inferred source models are in overall agreement with results from Pezzo et al. (2013), although small differences can be appreciated likely due to the impact of 3D modeling with respect to uniform modeling.

We then carried out a stress transfer analysis, based on the evaluation of the CFF variations, to ascertain if static stress was transferred after the main shock and triggered the second failure 9 days later. Previous works have reached contrasting results on the role of coseismic and postseismic (aseismic) stress transfer in promoting the May 29 earthquake (Ganas et al. 2012; Convertito et al. 2013; Pezzo et al. 2013). Our outcomes clearly reveal that the hypocentral area of the May 29 event was not loaded by the previous rupture, meaning that coseismic stress associated with the May 20 main shock did not act towards the rupture. Moreover, we also can exclude a mechanism involving indirect triggering due to an aseismic afterslip occurred at the eastern edge of the Mirandola fault.

In absence of a classical triggering mechanism due to stress transfer, new speculations could arise about the role of hydrocarbon exploitation in facilitating the failure, that the ICHESE (2014) report have not completely excluded. 
Our findings on the fluid pressure estimation reveal a suprahydrostatic regime acting on the May 29 rupture plane, which is supposed to contribute to activate the thrust, although the condition for hydraulic failure is not satisfied. This statement is still valid after the May 20 main shock, but notably the pressure variations induced by the event are found to act towards hydrofracturing, even if still not sufficient to overturn the above condition.

Acknowledgements The authors are grateful to the CalculiX and Cubit developers for the con-tinual software development and upgrading. We also thank Dr. G. Pezzofor sharing InSAR data. MV was funded by MIUR project "Studio multi-disciplinare della fase di preparazione di grandi terremoti".

\section{References}

Anderson EM (1951) The dynamics of faulting, 2nd edn. Oliver and Boyd, Edinburgh

Anzidei M, Maramai A, Montone P (2012) The Emilia (northern Italy) seismic sequence of May-June, 2012: preliminary data and results. Ann Geophys 55(4):842

Astiz L, Dieterich JH, Frohlich C, Hager BH, Juanes R, Shaw JH (2014) On the potential for induced seismicity at the Cavone oilfield: analysis of geological and geophysical data, and geomechanical modeling

Bignami C, Burrato P, Cannelli V, Chini M, Falcucci E, Ferretti A, Gori S, Kyriakopoulos C, Melini D, Moro M, Novali F, Saroli M, Stramondo S, Valensise G, Vannoli P (2012) Coseismic deformation pattern of the Emilia 2012 seismic sequence imaged by Radarsat-1 interferometry. Ann Geophys 55(4):789-795. doi:10.4401/ag-6157

Boschi L (2006) Global multiresolution models of surface wave propagation: comparing equivalently regularized Born and ray theoretical solutions. J Geophys Res 167:238-252. doi:10.1111/ j.1365-246X.2006.03084.x

Calderoni G, Di Giovambattista R, Burrato P, Ventura G (2009) A seismic sequence from Northern Apennines (Italy) provides new insight on the role of fluids in the active tectonics of accretionary wedges. Earth Planet Sci Lett 281:99-109. doi:10.1016/j.epsl. 2009.02.015

Casarotti E, Stupazzini M, Lee SJ, Komatitsch D, Piersanti A, Tromp J (2008) CUBIT and seismic wave propagation based upon the spectral-element method: an advanced unstructured mesher for complex 3D geological media. In: Brewer ML, Marcum D (eds) Proceedings of the 16th international meshing roundtable. Springer, New York, pp 579-597 (session 5B). doi:10.1007/ 978-3-540-75103-8_32

Cesca S, Braun T, Maccaferri F, Passarelli L, Rivalta E, Dahm T (2013) Source modelling of the M5-6 Emilia-Romagna, Italy, earthquakes (2012 May 20-29). J Geophys Res 193(3):1658-1672. doi:10.1093/gji/ggt069

Cocco M, Rice JR (2002) Pore pressure and poroelasticity effects in Coulomb stress analysis of earthquake interactions. J Geophys Res 107(B2). doi:10.1029/2000JB000138

Convertito V, Catalli F, Emolo A (2013) Combining stress transfer and source directivity: the case of the 2012 Emilia seismic sequence. Sci Rep 3:3114. doi:10.1038/srep03114

Dhondt G (2004) The finite element method for three-dimensional thermomechanical applications. Wiley, New York
Di Luccio F, Ventura G, Di Giovambattista R, Piscini A, Cinti FR (2010) Normal faults and thrusts reactivated by deep fluids: the 6 April $2009 \mathrm{M}_{w} 6.3$ L'Aquila earthquake, central Italy. J Geophys Res 115:B06315. doi:10.1029/2009JB007190

Di Stefano R, Chiarabba C, Chiaraluce L, Cocco M, De Gori P, Piccinini D, Valoroso L (2011) Fault zone properties affecting the rupture evolution of the 2009 (Mw 6.1) L'Aquila earthquake (central Italy): insights from seismic tomography. Geophys Res Lett 38:L10310. doi:10.1029/2011GL047365

Fournier RO (1996) Compressive and tensile failure at high fluid pressure where preexisting fractures have cohesive strength, with application to the San Andreas Fault. J Geophys Res 101(B11):25499-25509

Ganas A, Roumelioti Z, Chousianitis K (2012) Static stress transfer from the May 20, 2012, M 6.1 Emilia-Romagna (northern Italy) earthquake using a co-seismic slip distribution model. Ann Geophys 55(4):655-662. doi:10.4401/ag-6176

Govoni A, Marchetti A, De Gori P, Di Bona M, Lucente FP, Improta L, Chiarabba C, Nardi A, Margheriti L, Agostinetti NP, Di Giovambattista R, Latorre D, Anselmi M, Ciaccio MG, Moretti M, Castellano C, Piccinini D (2014) The 2012 Emilia seismic sequence (Northern Italy): imaging the thrust fault system by accurate aftershock location. Tectonophysics 622:44-55. doi:10. 1016/j.tecto.2014.02.013

Harris RA (1998) Introduction to special section: stress triggers, stress shadows, and implications for seismic hazard. J Geophys Res 103(B10):24347-24358

ICHESE, International Commission on Hydrocarbon Exploration and Seismicity in the Emilia Region (2014) Report on the hydrocarbon exploration and seismicity in Emilia region

Malagnini L, Lucente FP, De Gori P, Akinci A, Munafò I (2012) Control of pore fluid pressure diffusion on fault failure mode: insights from the 2009 LAquila seismic sequence. J Geophys Res 117:B05302. doi:10.1029/2011JB008911

Magnoni F, Casarotti E, Michelini A, Piersanti A, Komatitsch D, Peter D, Tromp J (2014) Spectral-element simulations of seismic waves generated by the 2009 L'Aquila earthquake. Bull Seismol Soc Am 104(1):73-94. doi:10.1785/0120130106

Mariucci MT, Müller B (2003) The tectonic regime in Italy inferred from borehole breakout data. Terra Nova 361(1-2):21-35. doi:10.1016/S0040-1951(02)00536-X

Meletti C, D'Amico V, Ameri G, Rovida A, Stucchi M (2012) Seismic hazard in the Po Plain and the 2012 Emilia earthquakes. Ann Geophys 55(4):623-629. doi:10.4401/ag-6158

Menke W (1989) Geophysical data analysis: discrete inverse theory. In: Internationalg geophysics series, vol 45. Academic Press Inc, San Diego

Michelini A, Faenza L, Lauciani V, Malagnini L (2008) ShakeMap implementation in Italy. Seismol Res Lett 79(5):688-697. doi: $10.1785 /$ gssrl.79.5.688

Miller SA, Collettini C, Chiaraluce L, Cocco M, Barchi M, Kaus BJP (2004) Aftershocks driven by a high-pressure $\mathrm{CO}_{2}$ source at depth. Nature 427:724-727. doi:10.1038/nature02251

MPS04, Redazione della mappa di pericolosit sismica prevista dall'Ordinanza PCM 3274 del 20 Marzo 2003, Rapporto Conclusivo per il Dipartimento della Protezione Civile, INGV, MilanoRoma, April 2004, 65 pp. Including 5 appendixes. http:// zonesismiche.mi.ingv.it. Accessed September 2009

Okada Y (1985) Surface deformation due to shear and tensile faults in a half-space. Bull Seismol Soc Am 75:1135-1154

Pezzo G, Merryman Boncori JP, Tolomei C, Salvi S, Atzori S, Antonioli A, Trasatti E, Novali F, Serpelloni E, Candela L, Giuliani R (2013) Coseismic deformation and source modeling of the May 2012 Emilia (Northern Italy) earthquakes. Seismol Res Lett 84(4):645-655. doi:10.1785/0220120171 
Scognamiglio L, Margheriti L, Mele F, Tinti E, Bono A, De Gori P, Lauciani V, Lucente FP, Mandiello AG, Marcocci C, Mazza S, Pintore S, Quintiliani M (2012) The 2012 Pianura Padana Emiliana seimic sequence: locations, moment tensors and magnitudes. Ann Geophys 55(4):549-559. doi:10.4401/ag-6159

Serpelloni E, Anderlini L, Avallone A, Cannelli V, Cavaliere A, Cheloni D, D'Ambrosio C, D'Anastasio E, Esposito A, Pietrantonio G, Pisani AR, Anzidei M, Cecere G, D'Agostino N, Del Mese S, Devoti R, Galvani A, Massucci A, Melini D, Riguzzi F, Selvaggi G, Sepe V (2012) GPS observations of coseismic deformation following the May 20 and 29, 2012, Emilia seismic events (northern Italy): data, analysis and preliminary models. Ann Geophys 55(4):759-766. doi:10.4401/ag-6168

Steacy S, Gomberg J, Cocco M (2005) Introduction to special section: stress transfer, earthquake triggering and time-dependent seismic hazard. J Geophys Res 110:B05S01. doi:10.1029/2005JB003692

Stein RS (1999) The role of stress transfer in earthquake occurrence (1999). Nature 402:605-609

Streit JE, Cox SF (2001) Fluid pressures at hypocenters of moderate to large earthquakes. J Geophys Res 106(B2):2235-2243. doi:10. 1029/2000JB900359

Tizzani P, Castaldo R, Solaro G, Pepe S, Bonano M, Casu F, Manunta M, Manzo M, Pepe A, Samsonov S, Lanari R, Sansosti E (2013) New insights into the 2012 Emilia (Italy) seismic sequence through advanced numerical modeling of ground deformation InSAR measurements. Geophys Res Lett 40:1971-1977. doi:10. $1002 /$ grl.50290
Ventura G, Di Giovambattista R (2013) Fluid pressure, stress field and propagation style of coalescescing thrusts from the analysis of the 20 May $2012 \mathrm{M}_{L} 5.9$ Emilia earthquake (Northern Apennines, Italy). Terra 25(1):72-78. doi:10.1111/ter.12007

Volpe M, Melini D, Piersanti A (2007) FEMSA: a finite element simulation tool for quasi-static deformation modeling. Ann Geophys 50:367-385

Volpe M, Melini D, Piersanti A (2011) Trade-off between seismic source detail and crustal heterogeneities in spherical 3d finite element modeling: the 2004 Sumatra earthquake case-study. Ann Geophys 54(1):91-103

Volpe M, Piersanti A, Melini D (2012) Complex 3-D finite element modelling of the 2009 April 6 LAquila earthquake by inverse analysis of static deformation. Geophys J Int 188:1339-1358. doi:10.1111/j.1365-246X.2011.05330.x

Volpe M, Atzori S, Piersanti A, Melini D (2015) The 2009 L'Aquila earthquake coseismic rupture: open issues and new insights from $3 \mathrm{~d}$ finite element inversion of Gps, InSAR and strong motion data. Ann Geophys 58(2):S0221. doi:10.4401/ag-6711

White DR, Kinney P (1997), Redesign of the paving algorithm: robustness enhancements through element by element meshing. In: Proceedings of 6th international meshing roundtable. Sandia National Laboratories, pp 323-335 